\title{
TWO VARIETIES OF HONEY THAT ARE AVAILABLE IN MALAYSIA GAVE INTERMEDIATE GLYCEMIC INDEX VALUES WHEN TESTED AMONG HEALTHY INDIVIDUALS
}

\author{
Sathyasurya Daniel Robert ${ }^{a *}$, Aziz Al-Safi Ismail ${ }^{\mathrm{b}}$ \\ a Program in Dietetics, School of Health Sciences, Universiti Sains Malaysia, Kelantan, Malaysia \\ ${ }^{b}$ Department of Community Medicine, School of Medical Sciences, Universiti Sains Malaysia, Kelantan, Malaysia \\ e-mail:dan77in@yahoo.com
}

Received: October 10, 2008; Accepted: January 2, 2009

Key words: Carbohydrate/Food/Glycemic index/Glucose/Honey/Humans

Aim: To determine the glycemic index (GI) of Malaysian wild honey and Australian honey.

Methods: Eight healthy volunteers ( 5 men and 3 women, aged $24-44$ y, with normal BMI) were served $50 \mathrm{~g}$ carbohydrate portions of two varieties of honey or the reference food (glucose, tested 3 times), on separate occasions. Capillary blood glucose was measured fasting and at 15, 30, 45, 60, 90 and 120 min after the start of the test meals. The GI was calculated by expressing each subject's incremental area under the blood glucose curve (AUC) after honey as a percentage of his or her mean AUC after glucose.

Results: The results showed that the mean AUC of the Malaysian and Australian honeys, $174 \pm 19$ and $158 \pm$ $16 \mathrm{mmol} \times \min / 1$, respectively, did not differ from each other but were significantly less than that after glucose, 259 $\pm 15 \mathrm{mmol} \times \min / 1(\mathrm{P}<0.001)$. The mean GI of Malaysian wild honey, $65 \pm 7$, did not differ from that of Australian honey, $59 \pm 5$, but both were significantly less than the GI of glucose, $100(\mathrm{P}<0.001)$.

Conclusions: We conclude that both Malaysian wild honey $(\mathrm{GI}=65 \pm 7)$ and Australian honey $(\mathrm{GI}=59 \pm 5)$ are intermediate GI foods.

\section{INTRODUCTION}

Dietary carbohydrates are usually classified into simple sugars and complex carbohydrates on the basis of their degree of polymerization. But according to the glycemic index (GI) concept dietary carbohydrates are classified according to their physiologic effects, specifically their ability to raise blood glucose, because the blood glucose response varies substantially among different carbohydrate-containing foods and cannot be predicted by their chemical composition ${ }^{1,2}$. The GI is therefore defined as the incremental area under the blood glucose response curve (AUC) after a portion of food containing $50 \mathrm{~g}$ available carbohydrate, expressed as a percentage of the response after $50 \mathrm{~g}$ glucose taken by the same subject ${ }^{3}$.

According to the international table of glycemic index, honey has a GI value ranging between 32 and 87 . This range is larger than can be accounted for by inter-laboratory variation and probably represents real differences between honeys ${ }^{4}$. Those honey varieties with the highest fructose to glucose ratio tend to have the lowest $\mathrm{GI}^{5}$. The GI of Malaysian honey is not yet determined. Therefore determining the GI of honey that is produced or available in Malaysia can have important implications for honey selection for specific situations. Therefore, the objective of this study was to determine the GI of Malaysian wild honey and Australian honey which is widely available in Malaysia.

\section{MATERIALS AND METHODS}

Study was conducted at the dietetics program, School of health sciences, Universiti Sains Malaysia using internationally recognized GI methodology ${ }^{6}$. This study was approved by the Ethics Review Committee for Human Subjects Research at Universiti Sains Malaysia, Kelantan, Malaysia, and informed consent was obtained from all subjects. Eight normal, healthy subjects ( 3 females and 5 males) aged $33 \pm 6$ y and a mean body mass index of $21.2 \pm 1.4 \mathrm{~kg} / \mathrm{m}^{2}$ participated in this study. The two varieties of honey selected for study were Malaysian wild honey (madu tualang, AgroMas, FAMA) and Australian honey (Wescobee Limited). Glucose (Glucolin ${ }^{\mathrm{TM}}$, The Boots Company, England) was used as the reference food. We studied the subjects on 5 different occasions in the morning after 10-12 hour overnight fasts. On three occasions, subjects consumed $50 \mathrm{~g}$ glucose dissolved in $400 \mathrm{ml}$ water. On the other two occasions each subject consumed a portion of one of the test foods, which contained $50 \mathrm{~g}$ available carbohydrates, defined as total carbohydrates by difference minus dietary fiber. The subjects were served with respective honeys using small cups and each subject consumed the honey in its original form, without any wastage. All test foods were served with a drink of $250 \mathrm{ml}$ water. Each subject consumed the test foods over a 10 to 13 min period. Finger prick capillary blood samples were taken fasting and at 15, 30, 45, 60, 90 and $120 \mathrm{~min}$ after starting to eat. Blood samples were taken 
into $1.5 \mathrm{ml}$ eppendorf tubes containing fluoride oxalate and were quickly centrifuged to obtain plasma, which was stored at $-20{ }^{\circ} \mathrm{C}$ prior to analysis of glucose using an auto analyzer (Spectra-E, Vitalab - Clinical Chemistry Analyser) which uses the glucose oxidase method.

\section{Data analysis}

Statistical analyses were conducted using Microsoft Excel Spread Sheets and the Statistics Program for Social Sciences (SPSS, version 12.1.0) computer software package. Incremental areas under the plasma glucose response curves (AUC), ignoring area beneath the fasting level, were calculated geometrically. The mean, SD and coefficient of variation $(\mathrm{CV}=100 \times \mathrm{SD} /$ mean $)$ of AUC values for repeated glucose tests for each subject were calculated. The AUC for each food was expressed as a percentage of the mean AUC for glucose taken by the same subject and the resulting values averaged to give the food GI. The AUC values and GI values of each subject were subjected to repeated measures ANOVA and, after demonstrating significant heterogeneity, the significance differences between individual means was assessed using Tukey's test to adjust for multiple comparisons. The criterion for significance was 2 -tailed $\mathrm{P}<0.05$. Results were expressed as mean \pm SEM.

\section{RESULTS}

The composition of the test meals, which was obtained from the food label, is shown in Table 1. The mean plasma glucose responses after the consumption of glucose and the test foods are shown in Fig. 1. The CV of the AUC of repeated glucose trials taken by 10 subjects was $20.9 \pm 4 \%$. The mean AUC after glucose, $259 \pm 15 \mathrm{mmol} \times \mathrm{min} / 1$ was significantly greater than those after Malaysian wild honey, $174 \pm 19 \mathrm{mmol} \times \mathrm{min} / 1$, and Australian honey, $158 \pm 16$ mmol $\times \min / 1(\mathrm{P}<0.001)$. Mean AUC after Malaysian wild honey did not differ $(P=0.33)$ from that after Australian honey. Similarly the mean GI of Malaysian wild honey, 65 \pm 7 was not $(\mathrm{P}=0.36)$ different from Australian honey, $59 \pm 5$, but both were significantly less than glucose, 100 $(\mathrm{P}<0.001)$.

\section{DISCUSSION}

Glycemic index of the two varieties of honey fell in the range (range $=32$ to $87 \%$ ) reported for other honeys 5 . The type of sugars that is present in the two types of honey was not estimated in this study. Based on scientific reports 100 grams of honey is composed of $41.8 \%$ of fructose, $34.6 \%$ of glucose, $17.5 \%$ of water, $0.4 \%$ of protein and trace amounts of sucrose and maltose ${ }^{7}$. The proportion of fructose present in honey is slightly higher than that of glucose. However, the fructose content of honey can be varied according to its floral source. Data given in the international tables state that the GI value of fructose is $19 \pm 2$ which is lower than that of glucose $(99 \pm 3)^{5}$. Certain findings state that pure fructose has a
Table 1. Composition of test meals

\begin{tabular}{|l|c|c|}
\hline \multicolumn{1}{|c|}{ Food } & $\begin{array}{c}\text { Malaysian Wild } \\
\text { Honey }\end{array}$ & $\begin{array}{c}\text { Australian } \\
\text { Honey }\end{array}$ \\
\hline Portion size (g) & 64.0 & 61.0 \\
\hline Protein $(\mathrm{g})$ & 0.1 & 0.2 \\
\hline Fat (g) & 0.0 & 0.0 \\
\hline Dietary Fiber (g) & 0.0 & 0.0 \\
\hline $\begin{array}{l}\text { Available } \\
\text { Carbohydrate (g) }\end{array}$ & 50.0 & 50.0 \\
\hline
\end{tabular}

I Data obtained from the food label

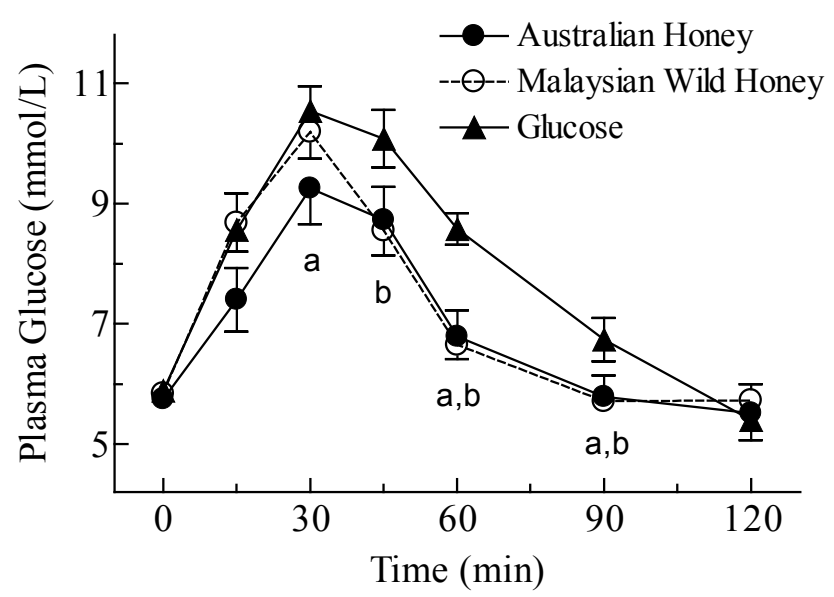

Values are means +/- SEM $(n=8)$

Comparison of plasma glucose concentrations $(P<0.05)$ : $\mathrm{a}=$ Australian Honey vs Glucose;

$\mathrm{b}=$ Malaysian Wild Honey vs Glucose.

Fig. 1.

GI value of 12, when measured against a glucose scale. This is because fructose is absorbed much slowly when consumed alone than when consumed together with other carbohydrate $^{8,9}$. As honey has equal sweetening capacity like that of the commonly used table sugar, it would be appropriate to compare both sweetening agents. The average GI value of honey given in the International table is $55 \pm 5$, whereas the average GI value for the table sugar is $68 \pm 5$. This means that honey may have lower blood glucose response than table sugar. But from this study it was found that the GI values of the Malaysian wild honey, $65 \pm 7$ and Australian honey, $59 \pm 5$ and the average GI value reported for table sugar ( GI $=68 \pm 5$ ) falls under the intermediate category $(56-69)^{5,10}$. Studies report that honey possesses natural antioxidants such as chrysin, pinobanksin, vitamin $\mathrm{C}$, catalase and pinocembrin that can decrease oxidative stress in humans ${ }^{11,12}$. Some studies also suggest that honey contains a variety of oligosaccharides that may act as prebiotics. Prebiotics are 
non-digestible dietary substances, which can promote the growth of beneficial bacteria (lactobacillus and bifidus) in the intestine. These beneficial microbes can suppress the overgrowth of harmful pathogens thereby improving gut health ${ }^{13}$. Furthermore, it has been shown that the GI value of honey was 32 when tested in persons with type 2 diabetes ${ }^{5}$. Thus, persons with diabetes mellitus can include moderate amounts of honey in a balanced diet. Hence, honey can be substituted for table sugar because of its additional health benefits. Further studies are needed to determine the composition of sugars present in the Malaysian honey varieties.

\section{CONCLUSIONS}

We conclude that Malaysian wild honey $(\mathrm{GI}=65 \pm 7)$ and Australian honey $(\mathrm{GI}=59 \pm 5)$ can be classified as intermediate GI foods.

\section{ACKNOWLEDGMENTS}

Universiti Sains Malaysia is thanked for the short-term grant. The author's wishes to thank Jamaruddin, Ahmed Hafizuddin, Chandran, Nurdiana, Nor Azzizah, Lukmi Ismail, Zaki Salamat, Sahnusi, Carolin Daniel and all the subjects for their help in conducting this study.

\section{REFERENCES}

1. Augustin LS, Franceschi S, Jenkins DJA, Kendall CWC, La Vecchia C. Glycemic index in chronic disease: a review. EuroJ of Clin Nutr 2002; 56:1049-71.

2. Wolever TMS. The glycemic index. World Review of Nutrition and Dietetics 1990; 62:120-85.

3. Wolever TMS, Jenkins DJA, Alexandra L Jenkins, Robert G Josse. The glycaemic index: methodology and clinical implications. American Journal of Clinical Nutrition 1991; 54:856-54.

4. Wolever TMS, Brand Miller J, Robert SD et al. Measuring the glycemic index of foods: interlaboratory study. Am J Clin Nutr 2008; 87:247S-57S.

5. Foster Powell K, Holt SH, Brand Miller JC. International table of glycemic index and glycemic load values 2002. American Journal of Clinical Nutrition 2002; 76:5-56.

6. Joint FAO/WHO Report, Carbohydrates in Human Nutrition. Rome: FAO: 1998.

7. Mark A Roe, Paul MF, Susan M Church, McCance and Widdowson's The Composition of Foods Sixth summary edition edn. (Cambridge: The Royal Society of Chemistry, Food Standard Agency, 2002), Pages.

8. Shi X, Schedl HP, Summers RM, Lambert GP, Chang RT, Xia T, Gisolfi CV. Fructose transport mechanisms in humans. Gastroenterology 1997; 113:1171-79.

9. Uusitupa. M. Fructose in the diabetic diet. Am J Clin Nutr 1994; 59:753s-57s.

10. Maria Kalergis, Elaine De Grandpre, Clare Andersons. The Role of the Glycemic Index in the Prevention and Management of Diabetes: A Review and Discussion. Canadian Journal Diabetes 2005, 29(1), 27-38

11. Gheldof N, Wang XH, Engeseth N. Buckwheat honey increases serum antioxidant capacity in humans. J Agric Food Chem 2003; 51:1500-05.

12. Gheldof N, Engeseth N. Antioxidant capacity of honeys from various floral sources based on the determination of oxygen radical absorbance capacity and inhibition of in vitro lipoprotein oxidation in human serum samples. J Agric Food Chem 2002; 50:3050-55.

13. Ustunol C, Gandhi H. Growth and viability of commercial bifidobacterium in honey-sweetened skim milk. J Food Prot 2001; 64:1775-79. 
